\title{
Effect of water-washed neem (Azadirachta indica) fruit on rumen digesta fatty acids and biohydrogenation intermediates of fattened West African dwarf rams
}

\author{
Akaninyene Asuquo Jack ${ }^{1 *}$, Michael Kolawole Adewumi², Okpara \\ Oghenesuvwe ${ }^{3}$, Moyosore Joseph Adegbeye ${ }^{4}$, Daniel Ekong Ekanem ${ }^{5}$, Tolulope \\ Oreoluwa Faniyi ${ }^{6}$
}

\author{
1,2,5 Department of Animal Science, University of Ibadan, Ibadan, Nigeria \\ ${ }^{3}$ Department of Animal Science, Delta State University, Delta State, Nigeria \\ ${ }^{4}$ Department of Animal Production and Health, Federal University of Technology Akure, Akure, Nigeria \\ ${ }^{6}$ Department of Animal Science, Ajayi Crowther University, Oyo, Oyo State, Nigeria \\ *Corresponding Author's
}

\begin{abstract}
This study was conducted to determine the rumen digesta fatty acid profile and biohydrogenation intermediates of West African dwarf rams fattened with diets containing water-washed neem (Azadirachta indica) fruit (WNF). Twenty-five yearling rams $(12.3 \pm 2.0 \mathrm{~kg})$ were assigned to one of the five dietary groups with five animals per group in a completely randomised design. Each group received a total mixed ration formulated with $0 \%$ (T1), 2.5\% (T2), 5.0\% (T3), 7.5\% (T4), and 10.0\% (T5) WNF inclusion for 90 days. Chemical analysis was carried out on WNF and the feed using standard procedures. Digesta was collected from the rumen after slaughtering the animals for the determination of fatty acids profile and biohydrogenation intermediates, after the feeding trial. Oleic, palmitic, stearic, and linoleic acids were not significantly $(P>0.05)$ affected by the different treatments. Rumenic acid was linearly lower $(P=0.006)$ in T1 compared to other treatments. The ratio of vaccenic to rumenic acids was linearly and quadratically reduced $(P=<0.001)$ with increased inclusion of WNF. Inclusion of WNF linearly and quadratically increased $(P=<0.001)$ DI-Rumenic acid. The PUFA/SFA was quadratically $(P=0.012)$ lower in T1 compared to T3. Inclusion of water-washed neem fruit in diets of rams increased the concentration of rumenicacid, a conjugated linoleic acid which when incorporated into the animal's tissue has health promoting benefits when consumed by man. Therefore, the proportion of rumenic acid in mutton should be boosted for increased incorporation into ruminant's tissues.
\end{abstract}

Keywords - Neem fruit, Biohydrogenation, Rumen digesta, Rumenic acid.

\section{INTRODUCTION}

The type, composition and activity of rumen microbes are of immense significance to the output of fermentation. This is key to the different strategies for better ruminal function especially, where most often, the output is a product of inefficiently used feed resources. Saturation of fatty acids in the rumen is one of the direct roles played by rumen microbes in an effort to detoxify the rumen ecosystem of excess hydrogen ion for their survival via biohydogenation. Therefore, the output of fat used in ruminant feeding could be improved upon through a proactive approach such as direct microbial interference that is based on an easy to adopt technology. 
The rumen is the habitat for a host of microbes which relate diversely as well as influence fermentative output in a variety of ways. Gram positive or negative bacteria can be suppressed or proliferated by feed constituents and this could either limit or enhance the activities of these microbes on fat alteration in the rumen leading to complete or incomplete metabolism with the production of intermediates. The selective elimination of gram positive bacteria by herbs including neem leaf and enhancement of the gram negatives (Faniyi, 2016) could result in better microbial output due to competitive advantage. Broudiscou et al. (2002) reported the enhancement of some microorganisms by some plant species concomitantly decreased methane production. Reduced methane generation increased conjugated fatty acid production due reduced protozoa or gram positive bacteria which limited the production and availability of hydrogen for biohydrogenation (Ramos Morales et al., 2012).

Neem (Azadirachta indica) fruit is medicinal and could be safely incorporated in ruminants' diets. Neem contains numerous phytochemicals not limited to margosate, nimbidin, nimbin, salanin tannin, saponin, flavonoid, alkaloid, glycoside, and terpenoids, at different concentrations in different plant parts but with proven antimicrobial properties. These phytochemical constituents when beyond the beneficial threshold limit its use. Waterwashing is one of the processing methods for increasing the acceptability and utilization of neem. The ability of neem leaf to increase the total number of beneficial microbes and digestibility in sheep (Faniyi, 2016; Faniyi, 2019) and the fruit to compete favourably with salinomycin in the reduction of coccidial egg count (Tipu et al., 2002; Jack et al., 2020) with reduced methane generation at 5\% optimal inclusion level (Jack, 2019) could play a significant role in increasing the efficiency of rumen fermentation and fatty acid transformation for better output. Therefore, rumen digesta fatty acid profile and biohydrogenation intermediates of West African dwarf rams fattened with diets containing waterwashed neem fruit were investigated.

\section{MATERIALS AND METHODS}

\subsection{Experimental site}

The experiment was undertaken at the Sheep and Goat Unit of the Teaching and Research Farm and the Ruminant Laboratory, Department of Animal Science of the University of Ibadan, Ibadan (latitude: $7^{\circ} 27^{\prime} \mathrm{N}$; longitude: $3^{\circ} 45^{\prime} \mathrm{E}$; altitude: $200-300 \mathrm{~m}$ above sea level; climate: humid tropical with mean annual rainfall of $1250 \mathrm{~mm}$ and average temperature of $25-29^{\circ} \mathrm{C}$ ) (Adewumi, 2010).

\subsection{Experimental animals, management, and diets}

Twenty-five healthy WAD rams (10-12 months) were divided into five groups of five animals in a randomised complete randomised design and housed in well-ventilated and concrete- floored pens containing feeders and waterers. Rams in each group were offered one of the five diets (Table 1). The experimental diets and potable water were offered $a d$ libitum at 0800 daily for 90 days. Prior to the commencement of the experiment diets, rams were offered the diet with $0 \%$ water-washed neem fruit inclusion and administered prophylactic treatments using Ivomec Super, Oxytetracycline (long acting) antibiotics, multivitamins and minerals and allowed a few weeks to acclimatise.

Table.1: Ingredient and chemical composition of experimental diets consumed by rams

\begin{tabular}{lccccc}
\hline \multirow{2}{*}{ Attributes } & \multicolumn{5}{c}{ Inclusion levels of water-washed neem fruit } \\
\cline { 2 - 4 } & $\mathbf{0 \%}$ & $\mathbf{2 . 5 \%}$ & $\mathbf{5 \%}$ & $\mathbf{7 . 5 \%}$ & $\mathbf{1 0 \%}$ \\
\hline Ingredients (\%) & & & & \\
Water-washed Neem Fruit & 0.00 & 2.50 & 5.00 & 7.50 & 10.00 \\
Cassava Peel & 53.00 & 50.50 & 48.00 & 45.50 & 43.00 \\
Dried Brewer's Grains & 10.00 & 10.00 & 10.00 & 10.00 & 10.00 \\
Palm Kernel Cake & 11.00 & 11.00 & 11.00 & 11.00 & 11.00 \\
Groundnut Haulms & 20.00 & 20.00 & 20.00 & 20.00 & 20.00 \\
DiCalcium Phosphate & 2.00 & 2.00 & 2.00 & 2.00 & 2.00 \\
Limestone & 1.00 & 1.00 & 1.00 & 1.00 & 1.00 \\
Grower's Premix* & 1.00 & 1.00 & 1.00 & 1.00 & 1.00 \\
\hline
\end{tabular}


International Journal of Environment, Agriculture and Biotechnology, 5(5)

Sep-Oct, 2020 / Available: https://ijeab.com/

\begin{tabular}{llllll}
\hline Salt & 1.00 & 1.00 & 1.00 & 1.00 & 1.00 \\
Urea & 1.00 & 1.00 & 1.00 & 1.00 & 1.00
\end{tabular}

Phytochemical composition of water-washed neem fruit (\% dry matter)

$\begin{array}{ll}\text { Margosate }(\mathrm{mg} / 100 \mathrm{~g}) & 64.33 \pm 2.52 \\ \text { Azadirachtin }(\mathrm{mg} / 100 \mathrm{~g}) & 218.33 \pm 2.52 \\ \text { Tannin }(\mu \mathrm{g} / 100 \mathrm{~g}) & 6.93 \pm 0.68 \\ \text { Saponin }(\mu \mathrm{g} / 100 \mathrm{~g}) & 321.67 \pm 7.96\end{array}$

Chemical composition (\%DM)

Crude protein $\quad 15.06$

Ether extract $\quad 2.20$

Neutral detergent fibre

43.67

15.14

15.62

15.62

15.70

2.24

2.28

2.32

2.36

Metabolisable energy $(\mathrm{Kcal} / \mathrm{Kg})$

2384.68

2366.68

2349.11

2342.70

2299.93

T1: Diet with 0\% Neem fruit; T2: Diet with 2.5\% neem fruit; T3: Diet with 5\% Neem fruit; T4: Diet with 7.5\% Neem fruit; T5: Diet with 10\% Neem fruit. *Vitamin A 8,000,000 I.U, Vitamin D3 1,7000000 I.U, Vitamin E 5000 mg, Vitamin K3 1500 mg, Folic Acid 200 mg, Niacin 1500 mg, Vitamin B2 3000 mg, Vitamin B12 5 mg, Vitamin B1 $1000 \mathrm{mg}$, Vitamin B6 $1000 \mathrm{mg}$, Iron 25,000 mg, Manganese $45000 \mathrm{mg}$, Copper $3000 \mathrm{mg}$, Zinc $35000 \mathrm{mg}$, Choline Chloride 100,000 mg

Source: Jack (2019).

Table.2: Fatty acid profile of digesta from WAD rams fattened with diets containing water-washed neem fruit

\begin{tabular}{|c|c|c|c|c|c|c|c|c|}
\hline \multirow{2}{*}{$\begin{array}{l}\text { Parameters ( } \mathrm{mg} / \mathrm{g} \text { of total } \\
\text { fatty acid) }\end{array}$} & \multicolumn{5}{|c|}{ Inclusion levels of water-washed neem fruit } & \multirow[t]{2}{*}{ SEM } & \multicolumn{2}{|c|}{ P-value } \\
\hline & $0 \%$ & $2.5 \%$ & $5 \%$ & $7.5 \%$ & $10 \%$ & & $\mathbf{L}$ & $\mathbf{Q}$ \\
\hline C12:0, lauric acid & 9.13 & 8.41 & 8.29 & 9.09 & 9.76 & 0.33 & 0.459 & 0.239 \\
\hline C14:0, myristic acid & 6.26 & 5.07 & 4.07 & 4.73 & 7.13 & 0.53 & 0.706 & 0.068 \\
\hline C16:0, palmitic acid & 32.03 & 28.42 & 28.76 & 24.70 & 33.14 & 1.64 & 0.903 & 0.194 \\
\hline C16:1, palmitoleic acid & 5.02 & 5.20 & 5.73 & 5.16 & 6.70 & 0.40 & 0.298 & 0.659 \\
\hline $\mathrm{C} 17: 0$, margaric acid & 0.90 & 0.67 & 0.43 & 0.78 & 1.37 & 0.18 & 0.449 & 0.187 \\
\hline C18:0, stearic acid & 25.13 & 24.74 & 24.60 & 25.17 & 25.60 & 0.34 & 0.635 & 0.489 \\
\hline C18:1, oleic acid & 94.97 & 108.90 & 102.29 & 88.84 & 122.06 & 5.46 & 0.387 & 0.493 \\
\hline C18:2, linoleic acid & 21.70 & 21.80 & 22.42 & 21.30 & 22.72 & 0.50 & 0.711 & 0.855 \\
\hline C18:3, linolenic acid & 10.17 & 10.09 & 11.40 & 10.61 & 11.44 & 0.40 & 0.341 & 0.941 \\
\hline C20:4, arachidonic acid & 2.72 & 3.74 & 4.16 & 3.72 & 4.04 & 0.27 & 0.201 & 0.345 \\
\hline
\end{tabular}

SEM: standard error of mean; L: linear regression; Q: quadratic regression.

2.3

Rumen digesta collection and fatty acid profile

ISSN: $2456-1878$

https://dx.doi.org/10.22161/ijeab.55.20
After 90 days of feeding, the rams were slaughtered after withdrawing feed except water for 16 hours and their 
respective rumen digesta sample collected into sterile containers and chilled until used for fatty acid analysis.

\section{$2.4 \quad$ Chemical analyses}

Proximate analysis, fibre fractions and phytochemical constituents of water-washed neem fruit and feed samples were done as reported in Jack (2019). Fatty acid profile was carried out according to AOCS (1978). Rumenic and vaccenic acids were determined using spectrophotometric method as described by AOAC (2005). Desaturase index was calculated as defined by Perfield li et al. (2007): [(product of $\Delta 9$-desaturase $) /($ product of $\Delta 9$-desaturase + substrate of $\Delta 9$ desaturase) ]. The estimation of polyunsaturated fatty acids (PUFA), monounsaturated fatty acids (MUFA), unsaturated fatty acids (UFA), and saturated fatty acids (SFA) were done by adding up the corresponding fatty acids determined from the sample (Miri et al., 2013).

\subsection{Statistical analysis}

Data obtained were analysed using Analysis of Variance (ANOVA) and General Linear Model procedure of SPSS (2006).

\section{RESULTS AND DISCUSSION}

\subsection{Fatty acid profile of rumen digesta}

Palmitic and stearic acids constituted $38.31-43.60 \%$ and $33.25-39.04 \%$ of the total saturated fatty acids, respectively while $68.08-72.98 \%$ of the unsaturated fatty acids were attributed to oleic acids (Table 2). All the contrasts tested were similar across the fatty acids (Table 2b). The differences in values of fatty acids obtained in this study and those reported by other researchers (Vasta et al 2010; Campidonico et al., 2016) could be a function of the age, breed, feed offered, duration of digesta collection after last feeding, and method of analysis. Alterations of fatty acid constituents in the rumen are reflective in fatty acid components of the muscle (Ya'ñez-Ruiz et al., 2007; Vasta et al., 2009). Increased saturated fatty acids in tissues consumed by man have been implicated in coronary heart disease in man (Menotti et al., 1999). However, with desaturation, saturated fatty acids known for their negative influence on human health can be altered. Desaturation can take place in the rumen, muscle and mammary gland of ruminants. Byers and Schelling (1993) reported the conversion of about $10 \%$ stearic acid to oleic in the enterocyte. Oleic acid, a mono unsaturated fatty acid can also be converted to vaccenic acid in the rumen (Jenkins et al., 2008) and mammary gland (Miri et al., 2013). Vaccenic is an intermediate of biohydrogenation and a precursor to rumenic acid that is known for its health promoting effect when consumed by man.

Table.2b: Fatty acid profile of digesta from WAD rams fattened with diets containing water-washed neem fruit

\begin{tabular}{|c|c|c|c|c|c|c|c|c|c|c|c|c|}
\hline \multirow{2}{*}{$\begin{array}{l}\text { Parameters } \\
\text { (mg/g of total } \\
\text { fatty acid) }\end{array}$} & \multicolumn{12}{|c|}{ P-Value for Contrast* } \\
\hline & 1 & 2 & 3 & 4 & 5 & 6 & 7 & 8 & 9 & 10 & 11 & 12 \\
\hline $\begin{array}{l}\text { C12:0, lauric } \\
\text { acid }\end{array}$ & 0.785 & 0.924 & 0.771 & 0.590 & 0.532 & 0.467 & 0.911 & 0.737 & 0.969 & 0.204 & 0.437 & 0.911 \\
\hline $\begin{array}{l}\text { C14:0, myristic } \\
\text { acid }\end{array}$ & 0.455 & 0.496 & 0.825 & 0.603 & 0.484 & 0.211 & 0.654 & 0.547 & 0.374 & 0.265 & 0.261 & 0.654 \\
\hline $\begin{array}{l}\text { C16:0, palmitic } \\
\text { acid }\end{array}$ & 0.456 & 0.485 & 0.517 & 0.840 & 0.515 & 0.554 & 0.820 & 0.669 & 0.200 & 0.932 & 0.474 & 0.820 \\
\hline $\begin{array}{l}\text { C16:1, } \\
\text { palmitoleic acid }\end{array}$ & 0.541 & 0.463 & 0.456 & 0.242 & 0.898 & 0.609 & 0.330 & 0.455 & 0.923 & 0.639 & 0.711 & 0.330 \\
\hline $\begin{array}{l}\mathrm{C} 17: 0 \text {, margaric } \\
\text { acid }\end{array}$ & 0.853 & 0.935 & 0.744 & 0.450 & 0.702 & 0.450 & 1.000 & 0.876 & 0.841 & 0.242 & 0.511 & 1.000 \\
\hline $\begin{array}{l}\text { C18:0, stearic } \\
\text { acid }\end{array}$ & 0.916 & 0.991 & 0.820 & 0.714 & 0.760 & 0.676 & 0.976 & 0.884 & 0.979 & 0.436 & 0.676 & 0.976 \\
\hline $\begin{array}{l}\text { C18:1, oleic } \\
\text { acid }\end{array}$ & 0.166 & 0.282 & 0.236 & 0.167 & 0.425 & 0.726 & 0.204 & 0.120 & 0.312 & 0.992 & 0.411 & 0.204 \\
\hline
\end{tabular}


International Journal of Environment, Agriculture and Biotechnology, 5(5)

Sep-Oct, 2020 / Available: https://ijeab.com/

$\begin{array}{lllllllllllll}\text { C18:2, linoleic } & 0.806 & 0.768 & 0.847 & 0.585 & 0.957 & 0.699 & 0.591 & 0.687 & 0.830 & 0.939 & 0.799 & 0.591\end{array}$

acid

$\begin{array}{lllllllllllll}\text { C18:3, linolenic } & 0.523 & 0.401 & 0.487 & 0.375 & 0.956 & 0.391 & 0.317 & 0.487 & 0.753 & 0.777 & 0.638 & 0.317\end{array}$

acid

$\begin{array}{lllllllllllll}\text { C20:4, } & 0.108 & 0.104 & 0.148 & 0.154 & 0.260 & 0.125 & 0.093 & 0.102 & 0.270 & 0.914 & 0.129 & 0.093\end{array}$

arachidonic acid

*Contrast values of $\mathrm{P}<0.05$ are significantly different; 1(WN0 Vs WN2.5, 5, 7.5, 10); 2(WN0 Vs WN5, 7.5, 10); 3(WN0 Vs WN7.5, 10); 4(WN0 Vs WN10); 5(WN0 Vs WN2.5); 6(WN0 Vs WN5); 7(WN0 Vs WN5,10); 8(WN0 Vs 2.5, 5, 10); 9(WN0 Vs WN7.5); 10(WN2.5, 5 Vs WN7.5,10); 11(WN0 Vs WN2.5, 5); 12(WN0 Vs WN5,10).

\subsection{Fatty acid intermediates and desaturase index of digesta}

Lower rumenic acids $(\mathrm{P}=0.006)$ was obtained in $\mathrm{T} 1$ compared to other treatments (Table 3). However, increased inclusion of WNF linearly and quadratically reduced VA/RA. Using contrast to compare the means, difference existed for RA except in contrast 5 and 10 while only contrast 10 was not affected in VA/RA (Table 3b). DI-16, DI-18, and total DI were not affected by the different contrast while DI-RA was affected by all the tested contrast. The increase in rumenic acid could be attributed to decreased microbial population and activities, and probably, increased desaturation of vaccenic acids. Increased rumenic acid could by implication be attributed to the reduction in the population of gram positive bacteria which probably could have resulted in the incomplete conversion of fatty acids that are unsaturated to stearic acid thus causing accumulation of intermediate products. Desaturation of precursors such as vaccenic acid could have played a major role as well since bacteria and fungi can undertake desaturation but not protozoa. Devillard et al. (2006) reported the inability of desaturation to occur in protozoal fraction of ruminal digesta.

Table.3: Fatty acid intermediates and desaturase index of digesta from WAD rams fattened with diets containing waterwashed neem fruit

\begin{tabular}{|c|c|c|c|c|c|c|c|c|}
\hline \multirow{2}{*}{$\begin{array}{l}\text { Parameters (mg/g of total fatty } \\
\text { acid) }\end{array}$} & \multicolumn{5}{|c|}{ Inclusion levels of water-washed neem fruit } & \multirow[t]{2}{*}{ SEM } & \multicolumn{2}{|c|}{ P-value } \\
\hline & 0\% & $2.5 \%$ & $5 \%$ & $7.5 \%$ & $10 \%$ & & $\mathbf{L}$ & $\mathbf{Q}$ \\
\hline C18:1 trans-11, Vaccenic acid & 0.06 & 0.04 & 0.05 & 0.05 & 0.05 & 0.001 & 0.455 & 0.101 \\
\hline C18:2 cis-9 trans-11 CLA, & 0.17 & 0.21 & 0.24 & 0.23 & 0.24 & 0.01 & 0.006 & 0.069 \\
\hline \multicolumn{9}{|l|}{ Rumenic acid } \\
\hline RA/LA & 0.01 & 0.01 & 0.01 & 0.01 & 0.01 & 0.0004 & 0.005 & 0.031 \\
\hline VA/RA & 0.33 & 0.20 & 0.20 & 0.21 & 0.21 & 0.01 & $<0.001$ & $<0.001$ \\
\hline $\mathrm{SA} / \mathrm{VA}$ & 453.16 & 576.16 & 498.71 & 523.93 & 516.70 & 14.39 & 0.378 & 0.132 \\
\hline DI-C16 & 0.14 & 0.15 & 0.16 & 0.17 & 0.17 & 0.01 & 0.114 & 0.553 \\
\hline DI-C18 & 0.79 & 0.81 & 0.80 & 0.78 & 0.82 & 0.01 & 0.496 & 0.477 \\
\hline DI- cis-9 trans-11 C18:2 CLA, & 0.76 & 0.83 & 0.83 & 0.83 & 0.83 & 0.01 & $<0.001$ & $<0.001$ \\
\hline \multicolumn{9}{|l|}{ Rumenic } \\
\hline Total DI & 0.58 & 0.63 & 0.61 & 0.59 & 0.62 & 0.01 & 0.324 & 0.511 \\
\hline
\end{tabular}


International Journal of Environment, Agriculture and Biotechnology, 5(5)

Sep-Oct, 2020 / Available: https://ijeab.com/

SEM: standard error of mean; LA: linoleic acid; RA: rumenic acid; VA: vaccenic acid; SA: stearic acid; DI: desaturase index; CLA: Conjugated linoleic acid; L: Linear regression; Q: Quadratic regression.

Table.3b: Fatty acid intermediates and desaturase index of digesta from WAD rams fattened with diets containing water-washed neem fruit

\begin{tabular}{|c|c|c|c|c|c|c|c|c|c|c|c|c|}
\hline \multirow{2}{*}{$\begin{array}{l}\text { Parameters }(\mathrm{mg} / \mathrm{g} \text { of } \\
\text { total fatty acid) }\end{array}$} & \multicolumn{12}{|c|}{ P-Value for Contrast* } \\
\hline & 1 & 2 & 3 & 4 & 5 & 6 & 7 & 8 & 9 & 10 & 11 & 12 \\
\hline $\begin{array}{l}\text { C18:1 trans-11, } \\
\text { Vaccenic acid }\end{array}$ & 0.011 & 0.003 & 0.007 & 0.088 & 0.180 & 0.016 & 0.012 & 0.033 & 0.040 & 0.512 & 0.082 & 0.012 \\
\hline $\begin{array}{l}\text { C18:2 cis-9 trans }-11 \\
\text { CLA, }\end{array}$ & 0.003 & 0.002 & 0.004 & 0.006 & 0.067 & 0.004 & 0.002 & 0.004 & 0.015 & 0.653 & 0.008 & 0.002 \\
\hline \multicolumn{13}{|l|}{ Rumenic acid } \\
\hline RA/LA & 0.002 & 0.002 & 0.003 & 0.008 & 0.058 & 0.004 & 0.002 & 0.004 & 0.005 & 0.518 & 0.007 & 0.002 \\
\hline VA/RA & 0.033 & 0.032 & 0.035 & 0.034 & 0.030 & 0.019 & 0.028 & 0.031 & 0.036 & 0.526 & 0.027 & 0.028 \\
\hline SA/VA & 0.025 & 0.071 & 0.058 & 0.111 & 0.007 & 0.238 & 0.114 & 0.026 & 0.080 & 0.520 & 0.023 & 0.114 \\
\hline DI-C16 & 0.140 & 0.110 & 0.104 & 0.154 & 0.457 & 0.261 & 0.146 & 0.183 & 0.151 & 0.441 & 0.283 & 0.146 \\
\hline DI-C18 & 0.272 & 0.456 & 0.370 & 0.146 & 0.179 & 0.784 & 0.266 & 0.144 & 0.277 & 0.804 & 0.390 & 0.266 \\
\hline $\begin{array}{l}\text { DI- cis-9 trans }-11 \\
\text { C18:2 CLA, }\end{array}$ & 0.028 & 0.027 & 0.031 & 0.030 & 0.024 & 0.013 & 0.023 & 0.025 & 0.031 & 0.521 & 0.021 & 0.023 \\
\hline \multicolumn{13}{|l|}{ Rumenic } \\
\hline Total DI & 0.305 & 0.359 & 0.377 & 0.224 & 0.197 & 0.389 & 0.269 & 0.238 & 0.649 & 0.419 & 0.248 & 0.269 \\
\hline
\end{tabular}

*Contrast values of $\mathrm{P}<0.05$ are significantly different; 1 (WN0 Vs WN2.5, 5, 7.5, 10); 2(WN0 Vs WN5, 7.5, 10); 3(WN0 Vs WN7.5, 10); 4(WN0 Vs WN10); 5(WN0 Vs WN2.5); 6(WN0 Vs WN5); 7(WN0 Vs WN5,10); 8(WN0 Vs 2.5, 5, 10); 9(WN0 Vs WN7.5); 10(WN2.5, 5 Vs WN7.5,10); 11(WN0 Vs WN2.5, 5); 12(WN0 Vs WN5,10).

Rumen biohydrogenation is initially carried out by grampositive bacteria and fungi and subsequently by gramnegative bacteria resulting in the isomerisation of linoleic acid to rumenic acid and the biohydrogenation of rumenic acid to vaccenic acid, and vaccenic acid to stearic acid, respectively (Kemp and Lander, 1984; Harfoot and
Hazzlewood, 1997; Nam and Garnsworthy, 2007). For linolenic acid, after isomerisation, it is followed by progressive hydrogenation to vaccenic acid and then to stearic acid (Kemp and Lander, 1984). Therefore, the ratio of RA/LA, VA/RA and SA/VA are indicative of the rate at which the process of ruminal biohydrogenation took place. 
Higher RA/LA indicated that isomerisation of linoleic acid to rumenic acid was favoured with increased inclusion of waterwashed neem fruit in the diets of rams. Lower VA/RA ratio pointed to the hindrance posed by incorporation of waterwashed neem fruit with respect to the conversion of rumenic acid to vaccenic acid. This could be attributed to reduced microbial activities of Group A bacteria and fungi responsible for the transformation of rumenic acid to vaccenic acid. Desaturation of unsaturated fatty acids in ruminal digesta by bacteria but not protozoa was reported by Devillard et al. (2006) and the ability of fungi (Piromyces communis) to desaturate stearic acid to oleic acid by Kemp et al. (1984). DI-rumenic increased with increased inclusion of neem fruit. This may be attributed to increased activity of delta 9-desaturase by bacteria and fungi in the microbial mass.

\subsection{Estimated fatty characteristics of rumen digesta}

Fatty acids as influenced by the different degrees of saturation were not affected by the treatments. However, PUFA/SFA was quadratically lower $(\mathrm{P}=0.012)$ in $\mathrm{T} 1$ compared to T3 (Table 4). Contrast was not affected in SFA, UFA, MUFA, PUFA, UFA/SFA. However, PUFA/SFA was affected by contrast $1,2,6$, and 11. Lower PUFA/SFA observed in the control indicated the increase production of SFA over PUFA. This could be as a result of the activities of increased protozoa and bacteria. The hydrogen producing activity of protozoa, fibrolytic fungi and bacteria, particularly gram positive bacteria in the rumen could have made reducing power available for the conversion of unsaturated fatty acids to vaccenic acid. This by implication means that there would have been no formation of stearic acid without the availability of vaccenic acid as provided mainly by the activities of gram positive bacteria. Long chain fatty acids (C18) have antimicrobial effect on bacteria which increased with increase extent of unsaturation with the cis-isomers being to a greater extent disruptive compared to transisomers (Chalupa et al., 1984) and this is in addition to the antimicrobial properties of the phytochemicals in neem fruit. The disruptive effect of these amphiphilic lipids are less on bacteria than on rumen protozoa and fungi (Ushida et al., 1992). Medium chain fatty acids have also been reported to defaunate the rumen in vivo (Machüller and Kreuzer, 1999) and lowered the population of methanogens in vitro (Jordan et al., 2006). These microbes have varying fatty acids composition which on destruction may probably form part of the biomass and would influence the fatty acid composition of the digesta.

Table.4. Estimated fatty acid characteristics of digesta from WAD rams fattened with diets containing water-washed neem fruit

\begin{tabular}{|c|c|c|c|c|c|c|c|c|}
\hline \multirow{2}{*}{$\begin{array}{l}\text { Parameters } \\
(\mathrm{mg} / \mathrm{g} \text { of total } \\
\text { fatty acid) }\end{array}$} & \multicolumn{5}{|c|}{ Inclusion levels of water-washed neem fruit } & \multirow[t]{2}{*}{ SEM } & \multicolumn{2}{|c|}{ P-value } \\
\hline & $0 \%$ & $2.5 \%$ & $5 \%$ & $7.5 \%$ & $10 \%$ & & $\mathbf{L}$ & $\mathbf{Q}$ \\
\hline SFA & 73.46 & 67.31 & 66.14 & 64.47 & 77.00 & 2.76 & 0.840 & 0.159 \\
\hline UFA & 134.81 & 149.99 & 146.30 & 129.91 & 167.26 & 6.69 & 0.370 & 0.588 \\
\hline MUFA & 100.04 & 114.14 & 108.07 & 94.05 & 128.81 & 5.79 & 0.375 & 0.500 \\
\hline PUFA & 34.76 & 35.85 & 38.23 & 35.86 & 38.45 & 1.09 & 0.403 & 0.866 \\
\hline UFA/SFA & 1.88 & 2.24 & 2.19 & 2.02 & 2.17 & 0.06 & 0.373 & 0.276 \\
\hline PUFA/SFA & 0.48 & 0.54 & 0.58 & 0.56 & 0.50 & 0.01 & 0.434 & 0.012 \\
\hline
\end{tabular}

SEM: standard error of mean. SFA: saturated fatty acid; UFA: unsaturated fatty acid; MUFA: monounsaturated fatty acid; PUFA: polyunsaturated fatty acid; L: Linear regression; Q: Quadratic regression. 
International Journal of Environment, Agriculture and Biotechnology, 5(5)

Sep-Oct, 2020 / Available: https://ijeab.com/

Table.4b: Estimated fatty acid characteristics of digesta from WAD rams fattened with diets containing water-washed neem fruit

\begin{tabular}{|c|c|c|c|c|c|c|c|c|c|c|c|c|}
\hline \multirow{2}{*}{\begin{tabular}{lr}
\multicolumn{2}{l}{ Parameters } \\
(mg/g of \\
total fatty \\
acid)
\end{tabular}} & \multicolumn{12}{|c|}{ P-Value for Contrast* } \\
\hline & $\mathbf{1}$ & 2 & 3 & 4 & 5 & 6 & 7 & 8 & 9 & 10 & 11 & 12 \\
\hline SFA & 0.528 & 0.582 & 0.738 & 0.706 & 0.517 & 0.443 & 0.817 & 0.668 & 0.349 & 0.550 & 0.416 & 0.817 \\
\hline UFA & 0.168 & 0.251 & 0.185 & 0.147 & 0.489 & 0.674 & 0.200 & 0.132 & 0.589 & 0.980 & 0.425 & 0.200 \\
\hline MUFA & 0.169 & 0.276 & 0.221 & 0.162 & 0.444 & 0.722 & 0.205 & 0.125 & 0.382 & 0.983 & 0.424 & 0.205 \\
\hline PUFA & 0.453 & 0.394 & 0.482 & 0.353 & 0.780 & 0.382 & 0.301 & 0.395 & 0.777 & 0.964 & 0.504 & 0.301 \\
\hline UFA/SFA & 0.285 & 0.325 & 0.376 & 0.265 & 0.197 & 0.315 & 0.256 & 0.231 & 0.542 & 0.340 & 0.218 & 0.256 \\
\hline PUFA/SFA & 0.044 & 0.045 & 0.131 & 0.526 & 0.123 & 0.020 & 0.077 & 0.064 & 0.053 & 0.286 & 0.028 & 0.077 \\
\hline
\end{tabular}

*Contrast values of $\mathrm{P}<0.05$ are significantly different; 1(WN0 Vs WN2.5, 5, 7.5, 10); 2(WN0 Vs WN5, 7.5, 10); 3(WN0 Vs WN7.5, 10); 4(WN0 Vs WN10); 5(WN0 Vs WN2.5); 6(WN0 Vs WN5); 7(WN0 Vs WN5,10); 8(WN0 Vs 2.5, 5, 10); 9(WN0 Vs WN7.5); 10(WN2.5, 5 Vs WN7.5,10); 11(WN0 Vs WN2.5, 5); 12(WN0 Vs WN5,10).

\section{CONCLUSION}

Increased inclusion of water-washed neem fruit increased the concentration of rumenic acid in the digesta. However, further inclusion beyond 5\% becomes unnecessary since the concentration of rumenic acid was similar. The increased concentration in digesta if passed down to ruminant tissues will be beneficial to humans when consumed. Rumenic acid is a conjugated fatty acid known for its health promoting benefits. Therefore, increasing the proportion of rumenic acid in mutton will go a long way in promoting health when made available to the tissues.

\section{FUNDING}

This research did not receive any specific grant from funding agencies in the public, commercial, or not-for-profit sectors.

\section{REFERENCES}

[1] Adewumi, M.K., 2010. Nutritive value of some crop residues with or without baker's Yeast (Saccharomyces cerevisiae) as supplements for West African dwarf sheep. Trop. Anim. Prod. Invest. 13(1), 7-12.

[2] AOAC, 2005. Determination of rumenic and vaccenic acids in biological samples. Official methods of analysis of Association of official Analytic Chemists. . International Gaithersbury, MD, USA,
[3] AOCS., 1978. Official and Tentative Methods of the American Oil Chemists Society, $3^{\text {rd }}$ edition, Champaign, Illinois, 203-207

[4] Broudiscou, L.P., Papon, Y., Broudiscou, A.F., 2002. Effects of dry plant extracts on feed degradation and the production of rumen microbial mass in a dual flow fermenter. Anim. Feed Sci. Technol. 101, 183-189. https://doi.org/10.1016/S0377$\underline{\text { 8401(02)00221-3 }}$

[5] Byers, F.M., Schelling, G.T. 1993. Lipids in ruminant nutrition, in: Church, DC (Ed), The ruminant animal: digestive physiology and nutrition. Waveland Press Inc., USA, pp 298-312

[6] Chalupa, W.. Rickabaugh, B., Kronfeld D.S.,Sklan, D., 1984. Rumen fermentation in vitro as influenced by long chain fany acids. J. Dairy Sci. 67,1439-1444. https://doi.org/10.3168/jds.s0022-0302(84)81459-9

[7] Campidonico, L., Toral, P.G., Priolo, A., Luciano, G., Valenti, B., Hervas, G., Frutos, P., Copani, G., Ginane, C., Niderkorn, V., 2016. Fatty acid composition of ruminal digesta and longissimus muscle from lambs fed silage mixtures including red clover, sainfoin, and timothy. J. anim. Sci. 94(4), 15501560. https://doi.org/10.2527/jas.2015-9922.

[8] Devillard, E., McIntosh, F.M., Newbold, C.J., Wallace, R.J., 2006. Rumen ciliate protozoa contain high concentrations of conjugated linoleic acids and vaccenic acid, yet do not hydrogenate linoleic acid and or desaturate stearic acid. Bri. J. Nutr. 96,697-704. https://doi.org/10.3168/jds.s00220302(84)81459-910.1079/BJN20061884

[9] Faniyi, T.O., 2016. Effects of some herbs and spices on rumen modulation in West African Dwarf sheep. Ph.D. Thesis, 
Department of Animal Science, University of Ibadan, Nigeria. pp 232

[10] Faniyi, T.O., Prates, E.R., Adegbeye, M.J., Adewumi, M.K., Elghandour, M.M.Y., Salem, A.Z.M., Ritt, L.A., Zubieta, A.S., Stella, L.., Ticiani, E., Jack, A.A., 2019. Prediction of biogas and pressure from rumen fermentation using plant extracts to enhance biodigestibility and mitigate biogases. Environmental Science and Pollution Research, 26:2704327051. https://doi.org/10.1007/s11356-019-05585-1

[11] Hook, S.E., Wright, A.G., McBride, B.W., 2010. Methanogens: Methane producers of the rumen and the mitigation strategies. Review Article. Archaea Volume 2010, Article ID 945785, 11, http://dx.doi.org/10.1155/2010/945785

[12] Harfoot, C., Hazlewood, G., 1997. Lipid metabolism in the rumen, in: Hobson, P.N., Stewart, C.S. (Eds), The rumen microbial ecosystem. Chapman and Hall, London, pp 382426.

[13] Jack, A.A., 2019 Effect of water-washing on chemical composition and in vitro biogas production of West African dwarf rams offered diets containing water-washed neem (Azadirachta indica) fruit. Nig. J. Agric. Food. Environ., 15(3), 43-52.

[14] Jack, A.A., Adewumi, M.K., Adegbeye, M.J., Ekanem, D.E., Salem, A.Z. M., Faniyi, T.O., 2020. Growth promoting effect of water-washed neem (Azadirachta indica A. Juss) fruit inclusion in West African dwarf rams. Trop. Anim. Health Prod. https://doi.org/10.1007/s11250-020-02380-w

[15] Jenkins, T.C., Wallace, R.J., Moate, P.J., Mosley, E.E., 2008. Review: Recent advances in biohydrogenation of unsaturated fatty acids within the rumen microbial ecosystem. J. Anim. Sci. 86 (2), 397-412. https://doi.org/10.2527/jas.2007-0588

[16] Jordan, E., Lovett, D.K., Hawkins, M., Callan, J.J., O’Mara, F.P., 2006. The effect of varying levels of coconut oil on intake, digestibility and methane output from continental cross beef heifers. Animal Science 82:859-865. https://doi.org/10.1017/ASC2006107

[17] Kemp, P., Lander, D.J., 1984. Hydrogenation in vitro of a linolenic acid to stearic acid by mixed culture of pure strains of rumen bacteria. J. Gen. Microbiol. 130, 527-533. https://doi.org/10.1099/00221287-130-3-527

[18] Kemp, P., Lander, D.J., Orpin, C.G., 1984. The lipids of the rumen fungus Piromonas communis. J. Gen. Microbiol. 130, 27-37. https://doi.org/10.1099/00221287-130-1-27

[19] Machüller, A., Kreuzer, M., 1999. Methane suppression by coconut oil and associated effects on nutrients and energy balance in sheep. Can. J. Anim. Sci. 79, 6572. https://doi.org/10.4141/A98-079

[20] Menotti, A., Krombout, D., Blackburn, H., Fidanza, F., Buzina, R., Nissinen, A. 1999. Food intake pattern and 25year mortality from coronary heart disease: Cross-cultural correlations in the Seven Countries Study. The Seven Countries Study Research Group. Eur. J. Epidemiol. 15:507515. https://doi.org/10.1023/a:1007529206050
[21] Miri, V.H., Tyagi, A.K., Ebrahimi, S.H., Mohini, M., 2013. Effect of cumin (Cuminum cyminum) seed extract on milk fatty acid profile and methane emission in lactating goats. Small Rum. Res. 113, 66-72. https://doi.org/10.1016/j.smallrumres.2013.01.015

[22] Nam, I.S., Garnsworthy, P.C., 2007. Biohydrogenation pathways for linoleic and linolenic acids by Orpinomyces rumen fungus. Asian-Austral. J. Anim. Sci. 20(11), 16941698. https://doi.org/ 10.5713/ajas.2007.1694

[23] Perfield Ii, J.W., Lock. A.L., Griinari, J.M., Sæbø, A., Delmonte, P., Dwyer, D.A., Beauman, D.E., 2007. Trans-9, cis-11 conjugated linoleic acid reduces milk fat synthesis in lactating dairy cows. J. Dairy Sci. 90, 22112218. https://doi.org/10.3168/jds.2006-745

[24] Ramos-Morales, E., Mata Espinosa, M.A., McKain, N., Wallace, R.J., 2012. Recinoleic acid inhibits methanogenesis and fatty acid biohydrogenation in ruminal digesta from sheep and in bacterial culture. J. Anim. Sci. http://dx.doi.org/10.2527/jas.2011-4670.

[25] SPSS., 2006. SPSS 15.0 for windows. SPSS Inc.www.spss.com

[26] Tipu, M.A., Pasha, T.N., Ali, Z. 2002. Comparative efficacy of salinomycin sodium and Neem fruit (Azadiracht indica) as feed additive anticoccidials in broilers. Inter. J. Poult. Sci. 1(4): 91-93.

[27] Ushida, K., Umeda, M., Kishigami, N., Kojima, Y. 1992. Effect of medium chain and long chain fatty acid calcium salts on rumen microorganisms and fibre digestion in sheep. Anim. Sci. Technol. (Japun) 63, 591-597.

[28] Vasta, V., Mele, V., Serra, A., Scerra, M., Luciano, G., Lanza, M., Priolo, A., 2009. Metabolic fate of fatty acids involved in ruminal biohydrogenation in sheep fed concentrate or herbage with or without tannins. J. Anim. Sci. 87:2674-2684. https://doi.org/10.2527/jas.2008-1761

[29] Vasta, V., Ya'ñez-Ruiz D.R., Mele M., Serra A., Luciano G., Lanza M., Biondi L., Priolo A., 2010. Bacterial and protozoal communities and fatty acid profile in the rumen of sheep fed a diet containing added tannins. Appl. Environ. Microbiol. 76(8), 2549-2555. https://doi.org/10.1128/AEM.02583-09_

[30] Ya'ñ̃ez-Ruiz, D.R., Williams, S., Newbold, C.J., 2007. Effect of the absence of protozoa on rumen biohydrogenation and the fatty acid composition of lamb muscle. Br. J. Nutr. 97:938-948. https://doi.org/10.1017/S0007114507675187 